\title{
The Effect of Multidentate Biopolymer Based on Polyacrylamide Grafted onto Kappa-Carrageenan on the Spectrofluorometric Properties of Water-Soluble CdS Quantum Dots
}

\author{
Ghasem Rezanejade Bardajee, Zari Hooshyar, and Yousof Pourhasan \\ Department of Chemistry, Payame Noor University, Tehran 19395-4697, Iran \\ Correspondence should be addressed to Ghasem Rezanejade Bardajee, ghrezanejad@yahoo.com
}

Received 20 July 2011; Revised 29 August 2011; Accepted 4 September 2011

Academic Editor: Jaan Laane

Copyright (C) 2011 Ghasem Rezanejade Bardajee et al. This is an open access article distributed under the Creative Commons Attribution License, which permits unrestricted use, distribution, and reproduction in any medium, provided the original work is properly cited.

\begin{abstract}
A new fluorescent composite based on CdS quantum dots immobilized on the multidentate biopolymer matrix is prepared through the graft copolymerization of the acrylamide onto kappa-Carrageenan. A variety of techniques like thermogravimetric analysis (TGA), transmission electron microscopy (TEM), and Fourier transform infrared spectroscopy (FT-IR) was used to confirm the structure of the obtained samples. To investigate the spectrofluorometric properties, fluorescence spectroscopy of the obtained quantum dots was studied.
\end{abstract}

\section{Introduction}

Semiconductor quantum dots (QDs), also called nanocrystals (NCs), have gained increasing attention in the past decade $[1-3]$. They have been widely investigated because of their potential use in sensors [4], laser materials [5], thinfilm light-emitting devices (LEDs) [6-8], and biological labels. Among numerous possible applications of QDs, biological labeling will be pointed out $[9,10]$. QDs exhibit larger photostability than organic dyes used routinely, since narrow excitation spectra of conventional dye molecules make difficult simultaneous excitation in most cases. However, QDs display size-dependent tunable florescence (FL) with broad excitation spectra and narrow emission band widths, which span the visible spectrum. This property of QDs allows simultaneous excitation of several particle sizes at a single wavelength, and therefore they facilitate multicolor experiments [11-14]. In addition, QDs have high photochemical stability, excellent resistance to chemical degradation and photodegradation, and good florescence quantum yields.

For most biological applications of QDs, their water solubility is indispensable. Three different approaches can be used to prepare water-soluble semiconductor QDs: ligand exchange $[15,16]$, encapsulation into a water-soluble shell (i.e., the silica or phospholipids) $[17,18]$, and surface coating with polymers $[19,20]$. In comparison, silica encapsulation produces good stability but with larger sizes which are about tens of nanometers to several micrometers [21]. In ligand exchange, the stability of the nanocrystals is limited by the stability of ligands on the QD surfaces. The proper choice of ligand is therefore crucial in order to achieve functionality and retain the optical properties of the QDs, and it usually limits the final application range of the QDs [22]. In this context, polymers may be used as suitable substitutes for the small organic ligand molecules due to their good stability on the surface of QDs [23].

A number of strategies were developed to obtain polymer-coated QDs: (1) the surface coating of amphiphilic polymers on the QDs surface by hydrophobic interactions between the surface ligands of nanocrystals and polymers [24]; (2) the attachment of multidentate polymeric ligands directly onto the QD surface via multiple or single bonds [25]; (3) the polymerization of polymeric chains directly from the QD surfaces [26]. However, most synthesized polymers in 


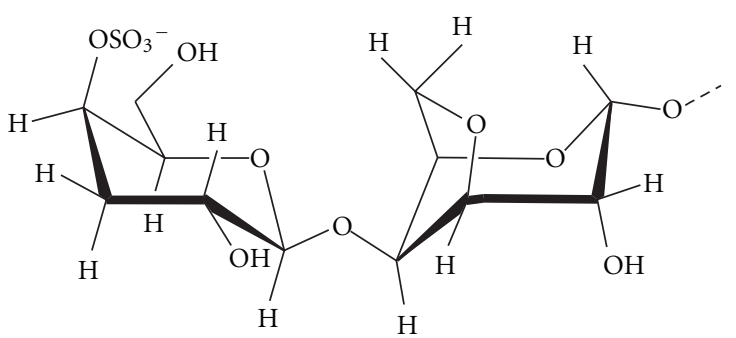

FIGURE 1: Chemical structure of kappa-carrageenan.

literatures are difficult to biodegrade and be further functionalized, which cannot meet the requirements of making low-cost, low-toxicity, and multifunctional water-soluble quantum dots.

Herein, we introduce a multidentateand natural biopolymer based on kappa-Carrageenan $(\kappa \mathrm{C})$ for preparation of CdS QDs with reasonable optical properties and high stability. $\kappa \mathrm{C}$ is a kind of sulfated polysaccharides extracted from red marine algae. It is widely utilized in the industry because it can form reasonably stiff and thermoreversible gels in the presence of so-called gel-promoting salts at room temperature [27]. This polysaccharide is linear polymer consisting of chains of $(1 \rightarrow 3)$-linked $\beta$-D-galactose and $(1 \rightarrow 4)$-linked $\alpha$-D-galactose units which are variously substituted and modified to the 3,6-anhydro derivative, depending on the source and extraction conditions [28-33]. Moreover, it is highly flexible molecules, which, at higher concentrations, wind around each other to form double-helical structures. A particular advantage is that they are thixotropic $[34,35]$, that is, they thin under shear stress and recover their viscosity once the stress is removed. Due to the strong ionic nature, it exhibits a high degree of reactivity. This material has been used in the field of drug delivery [36,37], which creates the potential for their use as drug delivery systems in tissue engineering. In view of this, it was chosen as a base for producing biopolymer derivatives (Figure 1).

\section{Materials and Methods}

2.1. Materials. Commercial grade cadmium sulfate $\left(\mathrm{CdSO}_{4} \cdot 8 \mathrm{H}_{2} \mathrm{O}, 99 \%\right)$, sodium thiosulfate $\left(\mathrm{Na}_{2} \mathrm{~S}_{2} \mathrm{O}_{3} \cdot 5 \mathrm{H}_{2} \mathrm{O}\right.$, 98\%), thioglycerol (TG, 98\%), acrylamide (AAm, 98\%), and ammonium persulfate (APS) were purchased from Merck. $\kappa$ Carrageenan $(\kappa \mathrm{C})$ was obtained from Condinson, Denmark. All chemicals and solvents were used without further purification. Double-distilled water was used for synthesis and optical measurements.

2.2. Instrumental Analysis. FT-IR spectra of samples in the form of $\mathrm{KBr}$ pellets were recorded using a Jasco $4200 \mathrm{FTIR}$ spectrophotometer. A Shimadzu UV-visible 1650 PC spectrophotometer was used for recording absorption spectra in solution. Fluorescence spectra were measured using SCINCO's Fluorescence Spectrometer FluoroMate FS-2. All samples were placed in a $1.00 \mathrm{~cm}$ quartz cuvette either for UV or fluorescence measurements. The dynamic weight loss tests

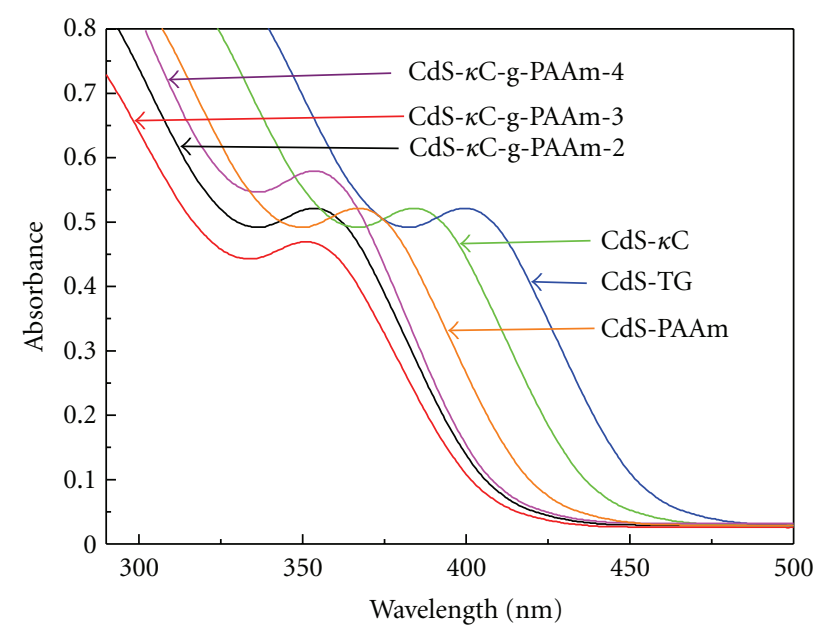

(a)

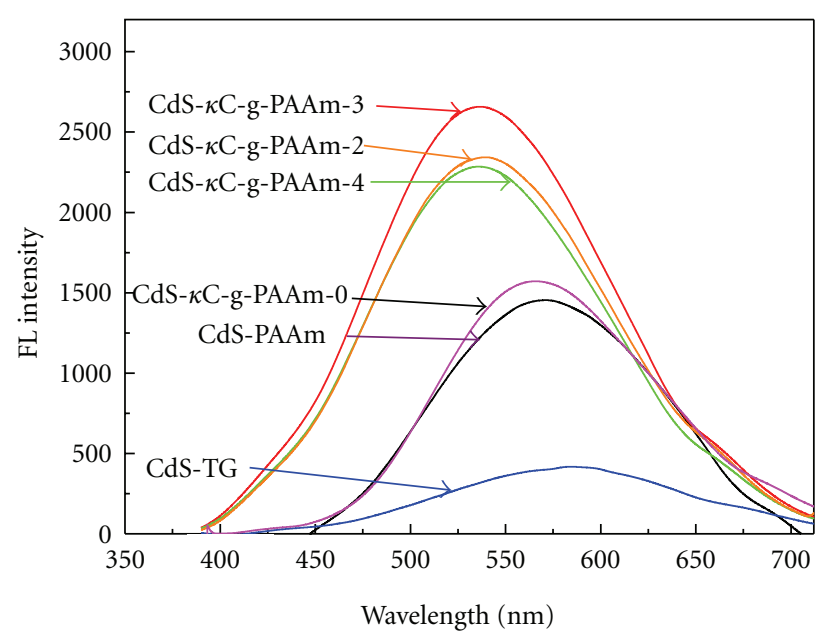

(b)

Figure 2: Comparison of (a) absorption, and (b) FL spectra of CdS$\kappa \mathrm{C}$-g-PAAm-0, CdS- $\kappa$ C-g-PAAm-2, CdS- $\kappa$ C-g-PAAm-3, CdS- $\kappa$ Cg-PAAm- 4 , and CdS-TG after 5 minutes stirring ( $\lambda_{\text {ex }}$ for emission spectra $=380 \mathrm{~nm}$ ) at room temperature.

were conducted on a TA instrument 2050 thermogravimetric analyzer (TGA). All tests were conducted under $\mathrm{N}_{2}$ atmosphere $(25 \mathrm{~mL} / \mathrm{min})$ using sample weights of $5-10 \mathrm{mg}$ over a temperature range of $25-750^{\circ} \mathrm{C}$ at a scan rate of $20^{\circ} \mathrm{C} / \mathrm{min}$. The mass of the sample pan was continuously recorded as a function of temperature. Transmission electron microscopy (TEM) was taken on a Zeiss TEM at an acceleration voltage of $80 \mathrm{kV}$. Samples for TEM were prepared by putting a drop of solution on a carbon-coated copper grid.

2.3. Sample Preparation. CdS QDs with maximum emission at $560 \mathrm{~nm}$ were synthesized using $\mathrm{CdSO}_{4} \cdot 8 \mathrm{H}_{2} \mathrm{O}$ and $\mathrm{Na}_{2} \mathrm{~S}_{2} \mathrm{O}_{3} \cdot 5 \mathrm{H}_{2} \mathrm{O}$ as the precursors and thioglycerol (TG) as the capping agent, according to a known procedure with some modifications [38, 39]. CdS QDs were thermally grown, and colloidal solutions were formed. In a typical procedure, $100 \mathrm{~mL}$ aqueous solution of the reactants and the capping agent was prepared while the concentrations of 


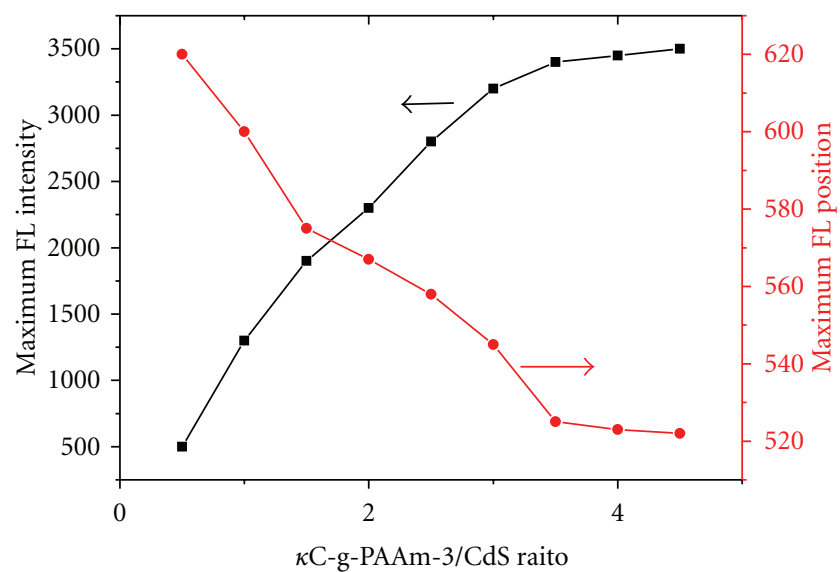

Figure 3: Comparison of maximum FL intensity and maximum FL position wavelength of CdS- $\kappa \mathrm{C}$-g-PAAm-3 depending on the $\kappa \mathrm{C}$-gPAAm-3/CdS ratio.

$\mathrm{CdSO}_{4} \cdot 8 \mathrm{H}_{2} \mathrm{O}, \mathrm{Na}_{2} \mathrm{~S}_{2} \mathrm{O}_{3} \cdot 5 \mathrm{H}_{2} \mathrm{O}$ and thioglycerol were 5,30 , and $400 \mathrm{mM}$, respectively. The $\mathrm{pH}$ was adjusted 8 by adding appropriate amounts of $\mathrm{NH}_{4} \mathrm{OH}$ solution. The reaction mixture was then heated at $100^{\circ} \mathrm{C}$ in an oil bath for $1 \mathrm{~h}$. For preparation of $\kappa$-Carrageenan grafted onto polyacrylamide $\left(\kappa \mathrm{C}\right.$-g-PAAm), $1 \mathrm{~g}$ of $\kappa \mathrm{C}$ was added to $\mathrm{H}_{2} \mathrm{O}(30 \mathrm{~mL})$ in a three-neck reactor equipped with a mechanical stirrer while stirring $(200 \mathrm{rpm})$. The reactor was immersed in a thermostated water bath preset at $80^{\circ} \mathrm{C}$. After homogenizing the mixture, three different amounts of AAm monomers (3, 4, and $5 \mathrm{~g}$ ) were added to the reaction mixture and stirred for further $20 \mathrm{~min}$. Then, APS $(0.15 \mathrm{~g})$ in $\mathrm{H}_{2} \mathrm{O}(5.0 \mathrm{~mL})$ was added and the reaction was started. After $30 \mathrm{~min}$, a viscous solution was formed. Then, synthesized CdS QDs was added to a transparent homogeneous solution of $\kappa \mathrm{C}$, polyacrylamide (PAAm), $\kappa$ C-g-PAAm-3 (means a graft copolymer sample which is prepared by mixing $1.0 \mathrm{~g} \kappa \mathrm{C}$ and $3 \mathrm{~g}$ PAAm), $\kappa \mathrm{C}$-g-PAAm-4 (means a graft copolymer sample which is prepared by mixing $1.0 \mathrm{~g} \kappa \mathrm{C}$ and $4 \mathrm{~g}$ PAAm), and $\kappa \mathrm{C}$-gPAAm-5 (means a graft copolymer sample which is prepared by mixing $1.0 \mathrm{~g} \kappa \mathrm{C}$ and $5 \mathrm{~g}$ PAAm). The solutions were stirred for $30 \mathrm{~min}$ at room temperature to ensure homogeneous and extensive diffusion of the QDs into the polymer chains. Meanwhile, the optical properties of the solution were studied through UV and FL measurements at different times. After that, the ethanol was added to the solution, centrifuged, and the remainder was collected for further experiments.

\section{Results and Discussion}

The absorption and FL spectra of CdS QDs, as taken from their reaction mixture with different ligands after 5 minutes stirring, are reported in Figure 2. Both spectra were obtained at room temperature. The absorption spectrum shows a main peak, ascribed to the first optically allowed transition between quantum confined state in conduction and valence band. The FL spectrum is dominated by a broad emission in the $400-700 \mathrm{~nm}$ region which can be attributed to different particle sizes of QDs. As shown in both absorption and FL spectra of Figure 2, the biopolymer influence the CdS

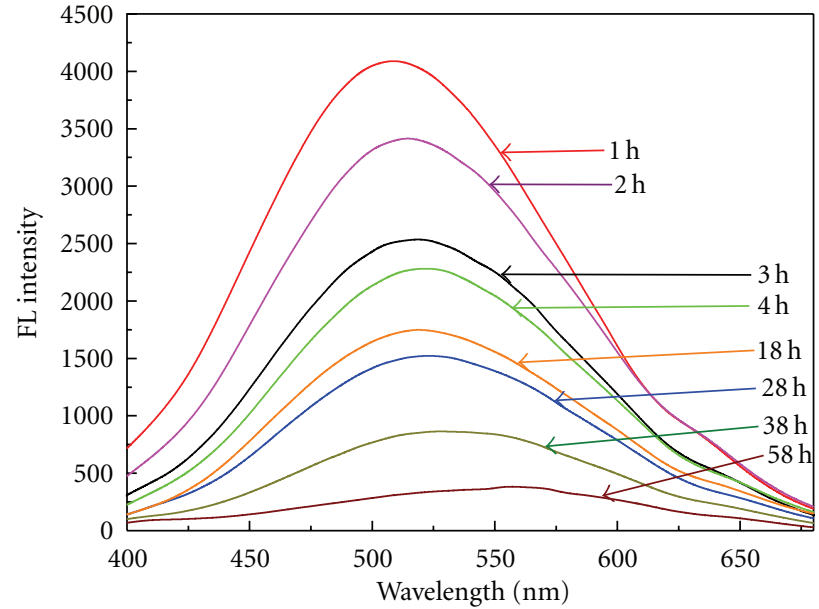

(a)

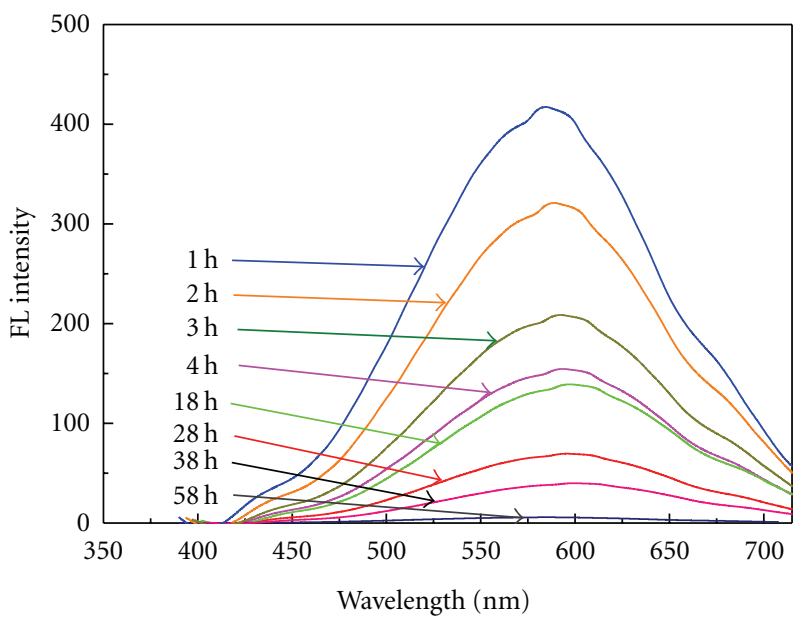

(b)

Figure 4: Comparison of FL spectra of (a) CdS- $\kappa$ C-g-PAAm-3, and (b) CdS-TG in different time intervals $\left(\lambda_{\mathrm{ex}}\right.$ for emission spectra $=$ $380 \mathrm{~nm}$ ) at room temperature.

QDs optical properties. Recent measurements indicate the important role of functional groups of polymer chains which interact with the surface of CdS QDs and increase the optical properties of CdS QDs [20, 21].

To test the influence of the $\kappa \mathrm{C}$-g-PAAm-3/CdS ratio on the optical properties of CdS- $\kappa \mathrm{C}$-g-PAAm-3, we kept all other experimental variables constant, and different amounts of KC-g-PAAm- 3 were added while the $\kappa \mathrm{C}$-g-PAAm-3/CdS molar ratio was adjusted to $0.5: 1,1: 1,1.5: 1,2: 1,2.5: 1$, $3: 1,3.5: 1,4: 1$, and $4.5: 1$. The temporal evolution of maximum FL intensity under different $\kappa \mathrm{C}$-g-PAAm-3/CdS ratio is shown in Figure 3. As one can see in Figure 3, the FL intensity increased monotonically to a maximum and then gradually fixed with the blue-shift of maximum FL intensity wavelength. At lower $\kappa \mathrm{C}$-g-PAAm-3/CdS ratio $(0.5: 1-1.5: 1)$, the maximum FL intensity is located at a longer wavelengths while in the case of higher $\kappa \mathrm{C}-\mathrm{g}$ PAAm-3/CdS ratio $(2: 1-4.5: 1)$, the maximum FL intensity is located at the shorter wavelengths. That is to say of higher $\kappa \mathrm{C}$-g-PAAm-3/CdS ratio favors the QDs with shorter 


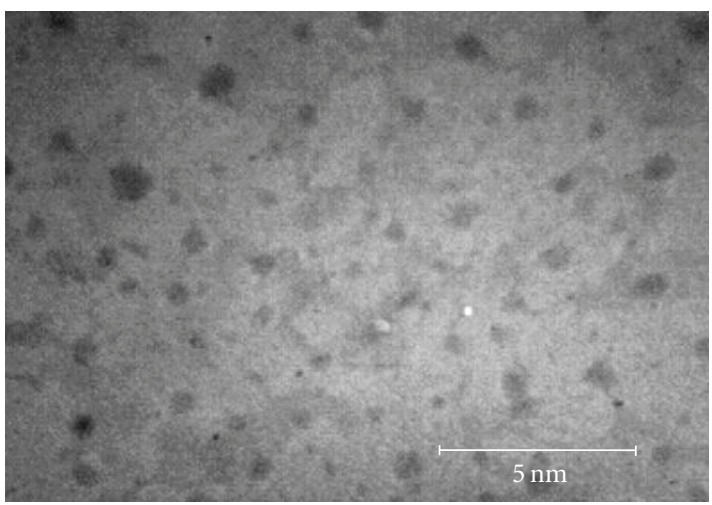

(a)

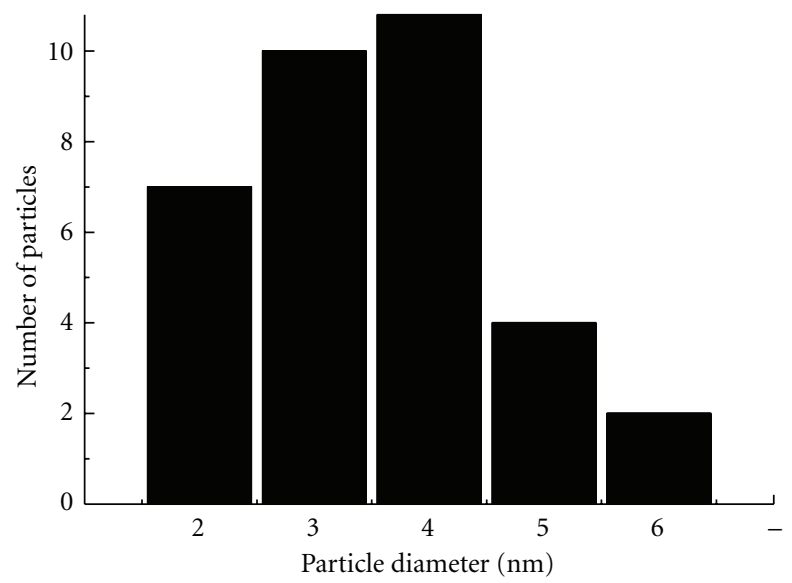

(b)

FIGURE 5: TEM images and the particle size histogram of the CdS$\kappa \mathrm{C}$-g-PAAm-3.

emission wavelengths; while lower $\kappa \mathrm{C}$-g-PAAm-3/CdS ratio favors for the QDs with longer emission wavelengths. The mechanism of the influence of $\kappa \mathrm{C}$-g-PAAm-3/CdS ratio on the optical properties of CdS QDs can be explained by aggregation of CdS QDs in lower $\kappa \mathrm{C}$-g-PAAm-3/CdS ratio and uniformly distribution of CdS QDs on $\kappa \mathrm{C}$-g-PAAm-3 matrix in higher $\kappa \mathrm{C}$-g-PAAm-3/CdS ratio.

Due to the sensitivity of the CdS QDs on processes occurring at the QDs surface, the stability of the FL became a very important parameter for the application of QDs in optoelectronic devices or luminescent labels. The study of temporal stability of FL intensity suggested that our synthesized CdS$\kappa \mathrm{C}$-g-PAAm-3 has a decline in optical properties over time (as shown in Figure 4 ). Nevertheless, while the CdS- $\kappa \mathrm{C}-\mathrm{g}-$ PAAm-3 had almost a strong FL intensity after $18 \mathrm{~h}$, the FL of CdS-TG quenched during this period. It is caused by the increasing the concentration of hydroxyl/amide groups on the surface of CdS QDs.

Figure 5 shows the transmission electron microscopy (TEM) image of CdS- $\kappa$ C-g-PAAm-3 along with its particle size histogram, which indicates a good dispersion of $\mathrm{CdS}$ QDs in $\kappa$ C-g-PAAm-3 matrix. According to this histogram, the CdS QDs has different particle sizes (mean size is about $4.2 \mathrm{~nm})$.

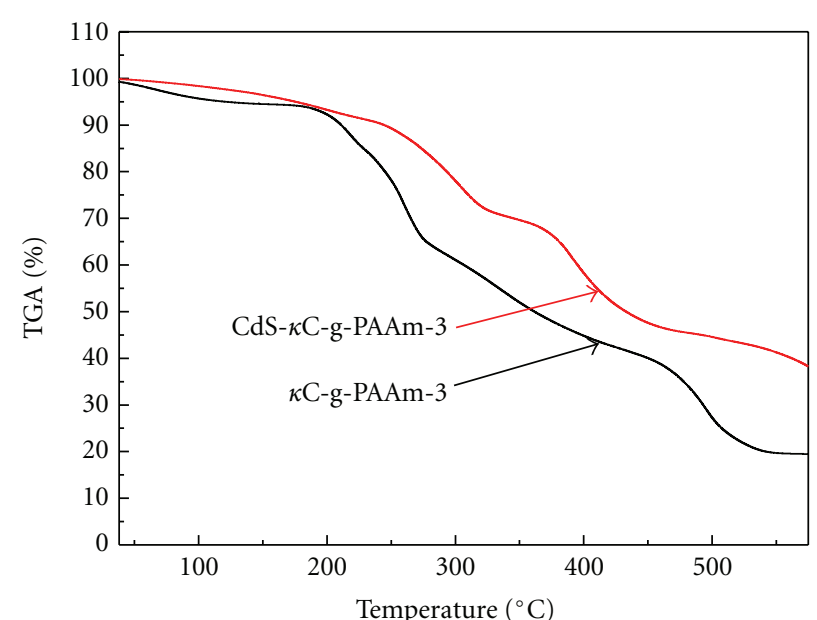

FIgURE 6: TGA curves of $\kappa \mathrm{C}$-g-PAAm-3 (before ligand exchange) and CdS- $\kappa$ C-g-PAAm-3 (after ligand exchange).

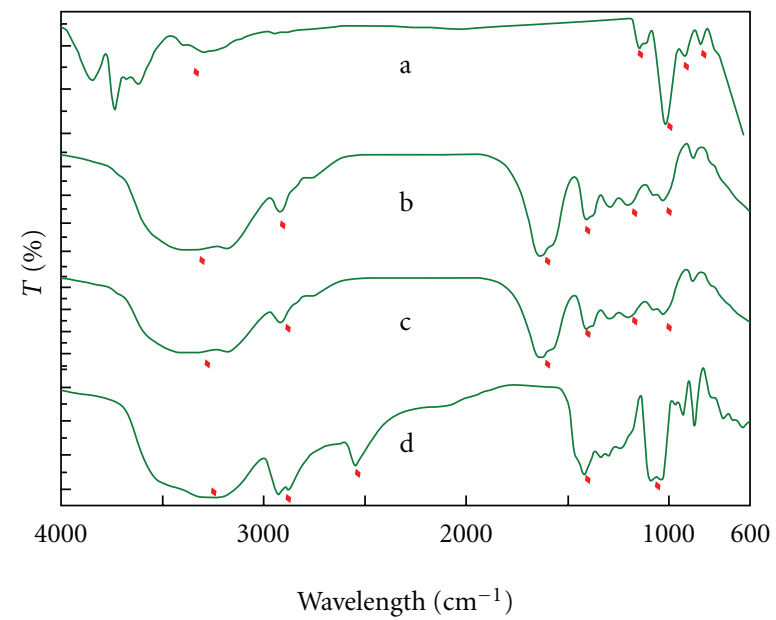

FIGURE 7: FT-IR spectra of (a) $\kappa$ C, (b) $\kappa$ C-g-PAAm-3, (c) CdS- $\kappa$ Cg-PAAm-3, and (d) CdS-TG.

In order to verify the presence of CdS QDs in $\kappa \mathrm{C}$-gPAAm-3, the thermogravimetric analysis (TGA) of CdS$\kappa \mathrm{C}$-g-PAAm-3 was compared with $\kappa \mathrm{C}$-g-PAAm-3 (Figure 6 ). Three degradation step appearing in the curve of CdS- $\kappa \mathrm{C}$-gPAAm- 3 is same to the curve of $\kappa$ C-g-PAAm- 3 , which means that CdS- $\kappa$ C-g-PAAm- 3 are produced. About $40 \mathrm{wt} . \%$ of the CdS- $\kappa$ C-g-PAAm-3 sample begins to decompose at $600^{\circ} \mathrm{C}$, higher than the decomposing of $\kappa$ C-g-PAAm-3 $(20 \%$ at $600^{\circ} \mathrm{C}$ ), denoting the formation of robust bonding between $\kappa \mathrm{C}$-g-PAAm-3 and CdS QDs. The actual content of CdS QDs in polymer matrix is calculated about $20 \mathrm{wt} . \%$.

Figure 7 shows the FT-IR spectra of $\kappa \mathrm{C}, \kappa \mathrm{C}$-g-PAAm3 , CdS- $\kappa$ C-g-PAAm-3, and CdS-TG. Figures $7(\mathrm{a})$ and $7(\mathrm{~b})$ show the FT-IR spectra of $\mathrm{kC}$ and $\kappa \mathrm{C}$-g-PAAm-3. The bands observed at $841,912,1016$, and $1220 \mathrm{~cm}^{-1}$ can be attributed to D-galactose-4-sulfate, 3,6-anhydro-D-galactose, glycoside linkage and ester sulfate stretching of $\kappa \mathrm{C}$, respectively (Figure $7(\mathrm{a}))$. The broad band at $3200-3400 \mathrm{~cm}^{-1}$ is due to stretching of $\mathrm{OH}$ groups in the polysaccharide substrate. 
The product, $\kappa \mathrm{C}$-g-PAAm- 3 comprises a $\kappa \mathrm{C}$ backbone with side chains that carry on carbonyl functional groups (from amide groups) which are evidenced by a broad doublet peak around $1660 \mathrm{~cm}^{-1}$ (Figure 7(b)). Figure 7(c) shows the FT-IR spectra of CdS- $\kappa$ C-g-PAAm-3 after ligand exchange process. It is clear that all main signals of $\kappa \mathrm{C}$-g-PAAm3 , copolymer $(\mathrm{OH}$ and amide stretching vibrations) are presented in Figure 7(c) which demonstrates the presence of biopolymers around the CdS QDs. The occurrence of a little shift in some signals of FT-IR spectrum in Figure 7(c) can be attributed to the chelating of the biopolymer functional groups on the surface of QDs. A representative FT-IR spectrum of the CdS-TG is illustrated in Figure 7(d). There is obvious difference between the FT-IR spectra of CdS-TG and the CdS- $\kappa \mathrm{C}$-g-PAAm-3. This indicates the formation of polymeric shell around CdS QDs.

\section{Conclusion}

In the present study, we report the synthesis of CdS- $\kappa \mathrm{C}$-gPAAm-3 with facile process at ambient temperature in water. It was observed that the FL intensity of CdS QDs was increased after embedment of CdS QDs into $\kappa \mathrm{C}$-g-PAAm-3 biopolymer-based matrix. It is worth to mention that the entitled biopolymer-conjugated QDs has high stability and marked optical properties besides being more eco-friendly.

\section{References}

[1] A. Fu, W. Gu, C. Larabell, and A. P. Alivisatos, "Semiconductor nanocrystals for biological imaging," Current Opinion in Neurobiology, vol. 15, no. 5, pp. 568-575, 2005.

[2] S. Zhong, L. Zhang, Z. Huang, and S. Wang, "Mixed-solvothermal synthesis of CdS micro/nanostructures and their optical properties," Applied Surface Science, vol. 257, no. 7, pp. 2599-2603, 2011.

[3] Y. F. Liu and J. S. Yu, "Selective synthesis of CdTe and high luminescence CdTe/CdS quantum dots: the effect of ligands," Journal of Colloid and Interface Science, vol. 333, no. 2, pp. 690698, 2009.

[4] O. L. Stroyuk, O. Y. Rayevska, A. V. Kozytskiy, and S. Y. Kuchmiy, "Electron energy factors in photocatalytic methylviologen reduction in the presence of semiconductor nanocrystals," Journal of Photochemistry and Photobiology A, vol. 210, no. 2-3, pp. 209-214, 2010.

[5] R. Karimzadeh, H. Aleali, and N. Mansour, "Thermal nonlinear refraction properties of $\mathrm{Ag}_{2} \mathrm{~S}$ semiconductor nanocrystals with its application as a low power optical limiter," Optics Communications, vol. 284, no. 9, pp. 2370-2375, 2011.

[6] T. Roques-Carmes Thibault, F. Aldeek, L. Balan, S. Corbel, and R. Schneider, "Aqueous dispersions of core/shell CdSe/CdS quantum dots as nanofluids for electrowetting," Colloids and Surfaces A, vol. 377, no. 1-3, pp. 278-283, 2011.

[7] H. Lee, S. Kim, W. S. Chung, K. Kim, and D. Kim, "Hybrid solar cells based on tetrapod nanocrystals: the effects of compositions and type II heterojunction on hybrid solar cell performance," Solar Energy Materials and Solar Cells, vol. 95, no. 2, pp. 446-452, 2011.

[8] Z. Cheng, F. Su, L. Pan, M. Cao, and Z. Sun, "CdS quantum dot-embedded silica film as luminescent down-shifting layer for crystalline Si solar cells," Journal of Alloys and Compounds, vol. 494, no. 1-2, pp. L7-L10, 2010.
[9] A. Papagiannaros, T. Levchenko, W. Hartner, D. Mongayt, and V. Torchilin, "Quantum dots encapsulated in phospholipid micelles for imaging and quantification of tumors in the nearinfrared region," Nanomedicine, vol. 5, no. 2, pp. 216-224, 2009.

[10] W. W. Yu, E. Chang, R. Drezek, and V. L. Colvin, "Watersoluble quantum dots for biomedical applications," Biochemical and Biophysical Research Communications, vol. 348, no. 3, pp. 781-786, 2006.

[11] G. R. Bardajee, C. Vancaeyzeele, J. C. Haley, A. Y. Li, and M. A. Winnik, "Synthesis, characterization, and energy transfer studies of dye-labeled poly(butyl methacrylate) latex particles prepared by miniemulsion polymerization," Polymer, vol. 48, no. 20, pp. 5839-5849, 2007.

[12] D. Andrews, G. Scholes, and G. Wiederrecht, Comprehensive Nanoscience and Technology, Academic Press, New York, NY, USA, 2010.

[13] X. C. Shen, X. Y. Liou, L. P. Ye, H. Liang, and Z. Y. Wang, "Spectroscopic studies on the interaction between human hemoglobin and CdS quantum dots," Journal of Colloid and Interface Science, vol. 311, no. 2, pp. 400-406, 2007.

[14] Z. Zhelev, R. Jose, T. Nagase et al., "Enhancement of the photoluminescence of CdSe quantum dots during long-term UV-irradiation: privilege or fault in life science research?" Journal of Photochemistry and Photobiology B, vol. 75, no. 12, pp. 99-105, 2004.

[15] S. Moeno, E. Antunes, and T. Nyokong, "The determination of the photosensitizing properties of mercapto substituted phthalocyanine derivatives in the presence of quantum dots capped with mercaptopropionic acid," Journal of Photochemistry and Photobiology A, vol. 218, no. 1, pp. 101-110, 2011.

[16] Y.-C. Yeh, D. Patra, B. Yan et al., "Synthesis of cationic quantum dots via a two-step ligand exchange process," Chemical Communications, vol. 47, no. 11, pp. 3069-3071, 2011.

[17] S. Pathak, S. K. Choi, N. Arnheim, and M. E. Thompson, "Hydroxylated quantum dots as luminescent probes for in situ hybridization," Journal of the American Chemical Society, vol. 123, no. 17, pp. 4103-4104, 2001.

[18] T. Kim, D. Choe, S. W. Joo, S. Y. Lee, and K. Lee, "Mathematical modeling of DNA-mediated selective aggregation of CdS quantum dots," Journal of Colloid and Interface Science, vol. 347, no. 2, pp. 209-214, 2010.

[19] N. Joumaa, M. Lansalot, A. Théretz et al., "Synthesis of quantum dot-tagged submicrometer polystyrene particles by miniemulsion polymerization," Langmuir, vol. 22, no. 4, pp. 1810-1816, 2006.

[20] V. I. Slaveykova and K. Startchev, "Effect of natural organic matter and green microalga on carboxyl-polyethylene glycol coated CdSe/ZnS quantum dots stability and transformations under freshwater conditions," Environmental Pollution, vol. 157, no. 12, pp. 3445-3450, 2009.

[21] A. Wolcott, D. Gerion, M. Visconte et al., "Silica-coated CdTe quantum dots functionalized with thiols for bioconjugation to IgG proteins," Journal of Physical Chemistry B, vol. 110, no. 11, pp. 5779-5789, 2006.

[22] I. D. Tomlinson, M. R. Warnerment, J. N. Mason et al., "Synthesis and characterization of a pegylated derivative of 3-(1,2,3,6-tetrahydro-pyridin-4yl)-1H-indole (IDT199): a high affinity SERT ligand for conjugation to quantum dots," Bioorganic and Medicinal Chemistry Letters, vol. 17, no. 20, pp. 5656-5660, 2007.

[23] B. Lounis, H. A. Bechtel, D. Gerion, P. Alivisatos, and W. E. Moerner, "Photon antibunching in single CdSe/ZnS quantum 
dot fluorescence," Chemical Physics Letters, vol. 329, no. 5-6, pp. 399-404, 2000.

[24] A. L. Rogach, A. Kornowski, M. Gao, A. Eychmüller, and H. Weller, "Synthesis and characterization of a size series of extremely small thiol-stabilized CdSe nanocrystals," Journal of Physical Chemistry B, vol. 103, no. 16, pp. 3065-3069, 1999.

[25] K. Sato, Y. Tachibana, S. Hattori, T. Chiba, and S. Kuwabata, "Polyacrylic acid coating of highly luminescent CdS nanocrystals for biological labeling applications," Journal of Colloid and Interface Science, vol. 324, no. 1-2, pp. 257-260, 2008.

[26] A. Emanuele, L. Di Stefano, D. Giacomazza, M. Trapanese, M. B. Palma-Vittorelli, and M. U. Palma, "Time-resolved study of network self-organization from a biopolymeric solution," Biopolymers, vol. 31, no. 7, pp. 859-868, 1991.

[27] M. R. Mangione, D. Giacomazza, D. Bulone, V. Martorana, and P. L. San Biagio, "Thermoreversible gelation of $\kappa$-Carrageenan: relation between conformational transition and aggregation," Biophysical Chemistry, vol. 104, no. 1, pp. 95-105, 2003.

[28] E. R. Morris, D. A. Rees, and G. Robinson, "Cation-specific aggregation of carrageenan helices: domain model of polymer gel structure," Journal of Molecular Biology, vol. 138, no. 2, pp. 349-362, 1980.

[29] P. L. San Biagio, D. Bulone, A. Emanuele, M. B. Palma-Vittorelli, and M. U. Palma, "Spontaneous symmetry-breaking pathways: time-resolved study of agarose gelation," Food Hydrocolloids, vol. 10, no. 1, pp. 91-97, 1996.

[30] A. M. Hermansson, "Rheological and microstructural evidence for transient states during gelation of kappa-carrageenan in the presence of potassium," Carbohydrate Polymers, vol. 10, no. 3, pp. 163-181, 1989.

[31] D. Slootmaekers, C. De Jonghe, H. Reynaers, F. A. Varkevisser, and C. J. Bloys van Treslong, "Static light scattering from $\kappa$-carrageenan solutions," International Journal of Biological Macromolecules, vol. 10, no. 3, pp. 160-168, 1988.

[32] L. Campanella, R. Roversi, M. P. Sammartino, and M. Tomassetti, "Hydrogen peroxide determination in pharmaceutical formulations and cosmetics using a new catalase biosensor," Journal of Pharmaceutical and Biomedical Analysis, vol. 18, no. 1-2, pp. 105-116, 1998.

[33] M. F. Perutz, "Glutamine repeats and inherited neua-rodegenerative diseases: molecular aspects," Current Opinion in Structural Biology, vol. 6, no. 6, pp. 848-858, 1996.

[34] K. Makino, R. Idenuma, T. Murakami, and H. Ohshima, "Design of a rate- and time-programming drug release device using a hydrogel: pulsatile drug release from $\kappa$-carrageenan hydrogel device by surface erosion of the hydrogel," Colloids and Surfaces B, vol. 20, no. 4, pp. 355-359, 2001.

[35] C. Rochas, M. Rinaudo, and S. Landry, "Relation between the molecular structure and mechanical properties of carrageenan gels," Carbohydrate Polymers, vol. 10, no. 2, pp. 115-127, 1989.

[36] R. M. Murphy, "Peptide aggregation in neurodegenerative disease," Annual Review of Biomedical Engineering, vol. 4, pp. 155-174, 2002.

[37] A. M. Garcia and E. S. Ghaly, "Preliminary spherical agglomerates of water soluble drug using natural polymer and crosslinking technique," Journal of Controlled Release, vol. 40, no. 3, pp. 179-186, 1996.

[38] M. Marandi, N. Taghavinia, A. Iraji Zad, and S. M. Mahdavi, "A photochemical method for controlling the size of CdS nanoparticles," Nanotechnology, vol. 16, no. 2, pp. 334-338, 2005.

[39] Z. Sedaghat, N. Taghavinia, and M. Marandi, "Thermal control of the size and crystalline phase of CdS nanoparticles," $\mathrm{Na}$ notechnology, vol. 17, no. 15, article 034, pp. 3812-3816, 2006. 


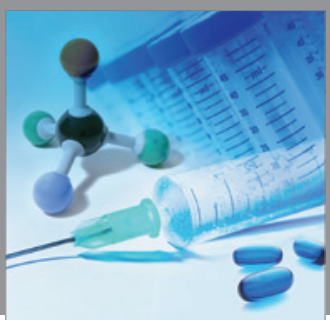

International Journal of

Medicinal Chemistry

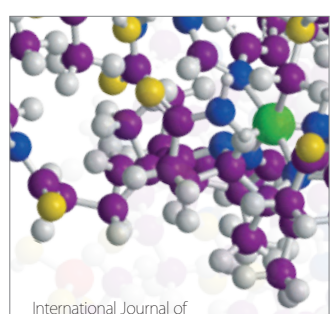

Carbohydrate Chemistry

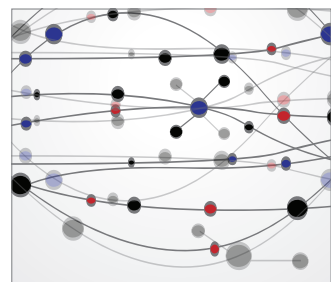

The Scientific World Journal
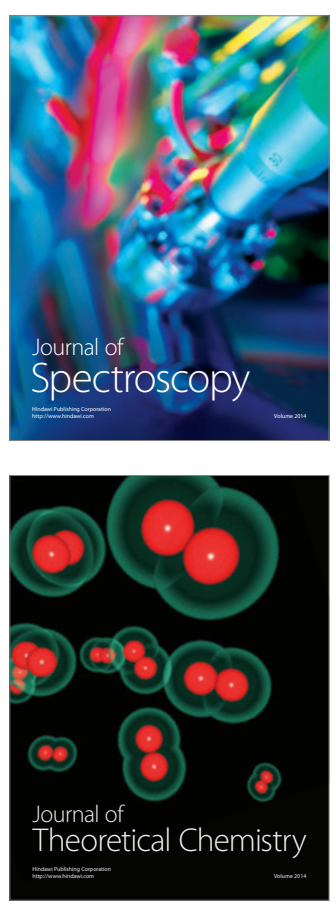
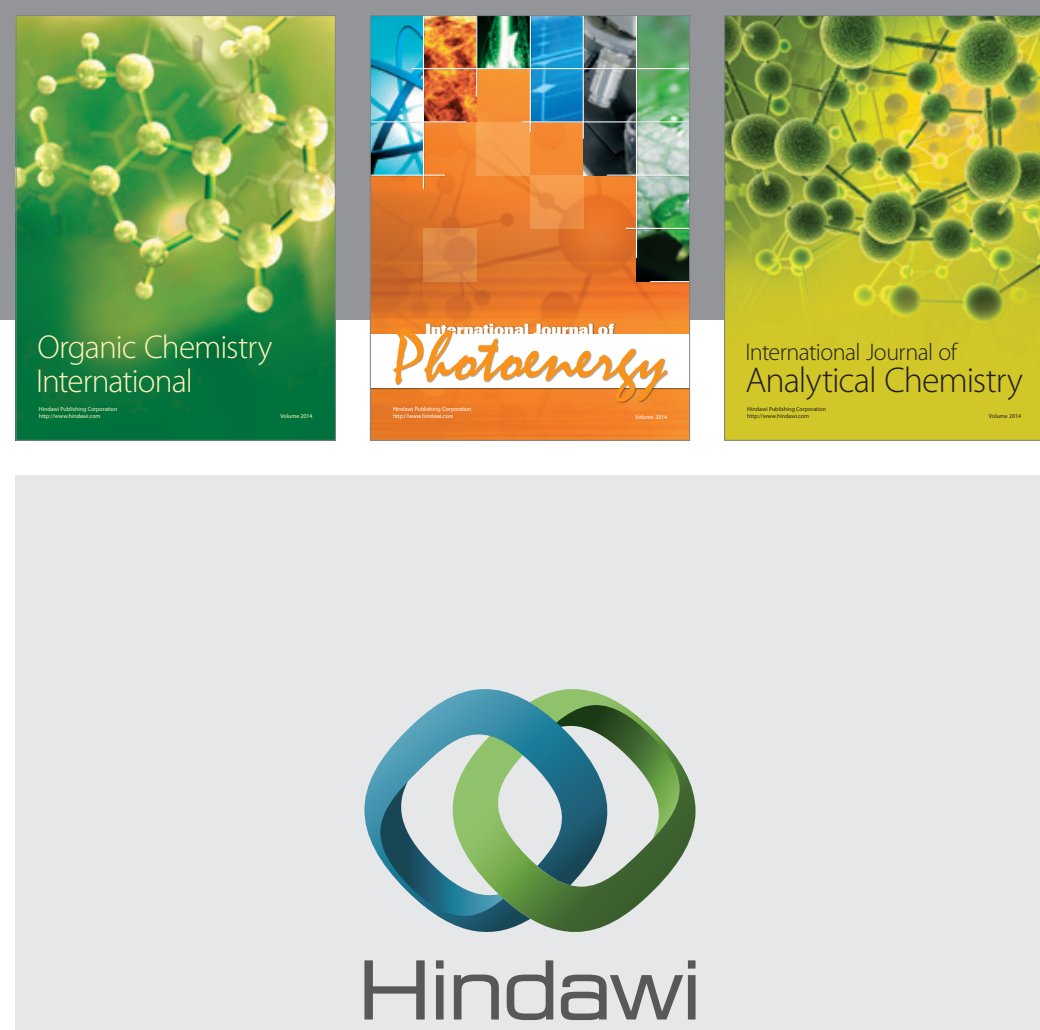

Submit your manuscripts at

http://www.hindawi.com
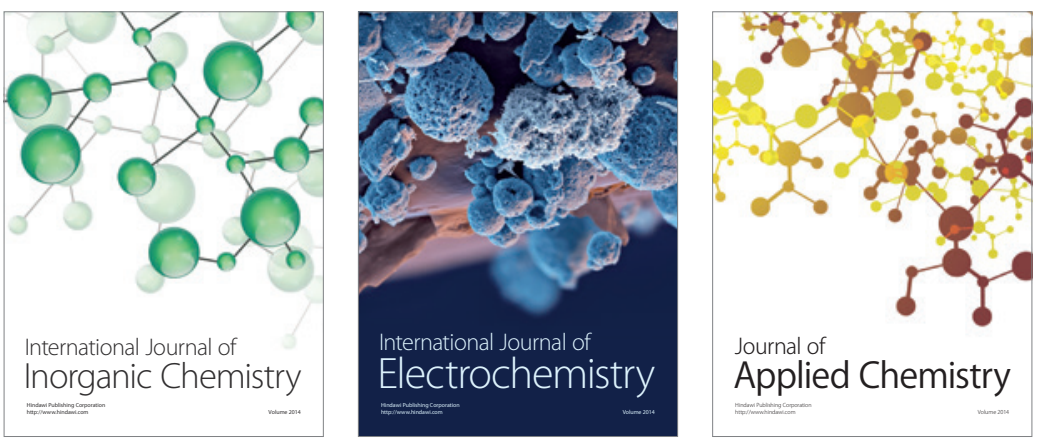

Journal of

Applied Chemistry
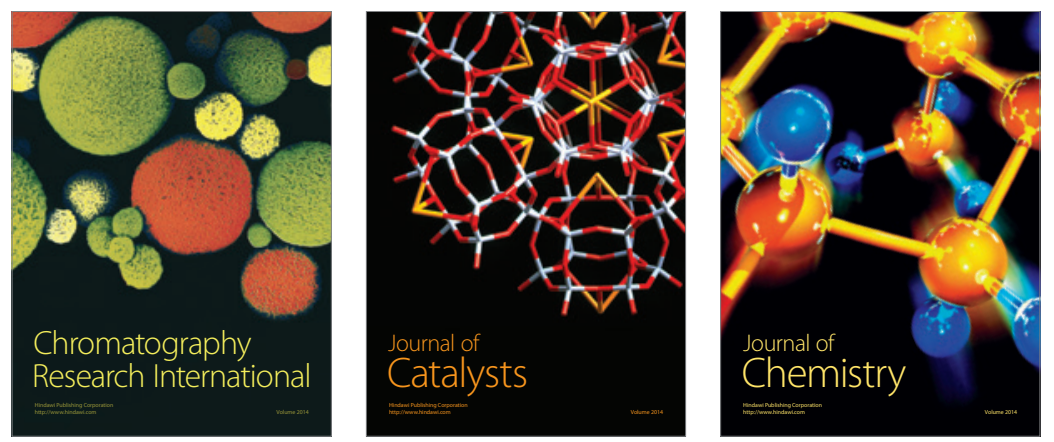
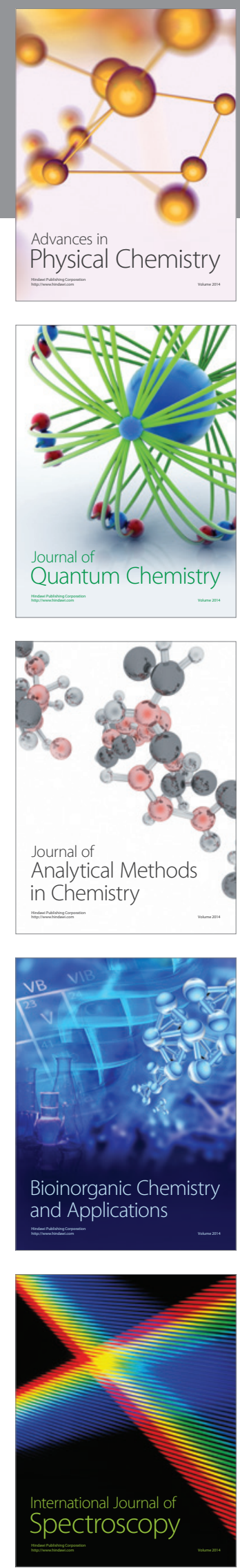